DIVISION OF THE HUMANITIES AND SOCIAL SCIENCES

CALIFORNIA INSTITUTE OF TECHNOLOGY

PASADENA, CALIFORNIA 91125

REPUTATION AND PRODUCT QUALITY

William P. Rogerson

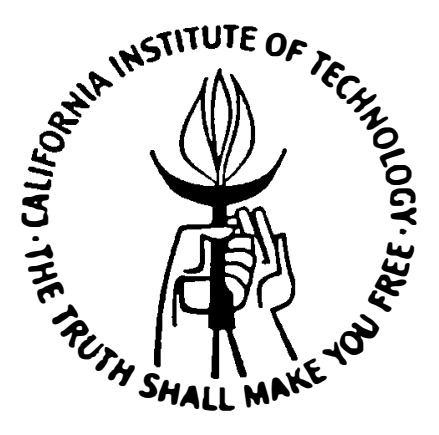

SOCIAL SCIENCE WORKING PAPER 330

July 1980 


\section{REPUTATION AND PRODUCT QUALITY}

William P. Rogerson

ABSTRACT

This paper examines a market where buyers cannot judge the quality of the good they receive until after they consume it. Even then, they may make mistakes in their judgments. The paper derives the equilibrium quality distribution for goods produced and the equilibrium distribution of firms by the quality of good they produce, and identifies the specific factors which produce a reputation effect. Comparative statics allow analysis of the effects of restrictions on information flow and barriers to entry.

\section{INTRODUCTION}

A large fraction of economic activity is organized on the basis of contracts which are either legally unenforceable or at least unenforceable in practice. As the actions of parties to some joint economic activity become more complex or difficult for third parties to verify, two costs of contracting begin to grow larger. First, the enforcement and litigation costs begin to grow. Second, the transactions costs of drafting a contract which adequately describes the contemplated actions grow larger. The first cost tends to produce the situation that even if a contract is legally enforceable, it is in practice nonenforceable because the size of litigation and enforcement costs relative to the gains from performance make the option of legal enforcement unattractive. The second cost tends to produce the situation that actions are not adequately specified to be legally enforceable. In both situations, parties to a contract find themselves in the position where they need not fear legal sanctions for breaching a contractual obligation, yet they often do honor these obligations even when their apparent interests lie in breaching.

*This paper was written while I was supported by a Canada Council Doctoral Fellowship. I would like to thank Robert Bates, Ed Green, Roger Noll, Alan Schwartz, and Louis Wilde for helpful discussions. 
Economists have traditionally rationalized such behavior In the context of a world of self-interested actors by reference to "reputation." Economic actors operating on the basis of self-interest may well honor non binding contracts that appear not to be in their short run interest if future opportunities depend on adequate performance of current obligations. In this case contracts merely provide parties with a mutual basis for understanding what their obligations to one another are. A growing literature is examining the micro-foundations of such behavior from a repeated games standpoint (Green, 1980; Radner, 1979; Rubinstein, 1979; Townsend, 1979). Less attention, however, has been pald to the other perspective from which economists typically analyze a problem -behavior of markets as a whole.

This paper models behavior of a market where product quality can vary and consumers cannot determine this quality prior to purchase. The "contract" being considered is the firm's promise to supply a high quality good. Ackerlof (1970) was one of the first to consider such a market. He pointed out that if firms could not be differentiated by consumers and if consumers did not belleve that a firm would continue to produce at its past quality level, then firms would all produce the lowest quality of goods. A market of "lemons" would result. The starting point of this paper is the assumption that a firm can build a reputation -- firms can be differentiated by consumers and consumers believe that the quality of a firm's performance in the future will be related to its performance in the past. This situation has been extensively analyzed (Klein and
Leffler 1979; Dybvig and Spatt 1980) under the assumption that consumers can judge quality with complete accuracy once they have recelved the good. Under this assumption, firms which misrepresent quality have a lifetime of one period. These papers are thus in a sense on the economics of "fly by night operators."

A very large class of goods does not satisfy this assumption of perfect consumer accuracy. In particular, consumers are of ten capable of performing only very partial and vague evaluations of the quality of professional services they receive from doctors, lawyers, banks, mechanics, opticlans, etc. Furthermore, the quality of a service from a given professional may vary from time to time. This combination of observer error and actual quality variance makes it difficult for consumers to correctly evaluate the quality of service that a firm produces. In such a market a producer can contemplate staying in the market over the long run even if he misrepresents the quality of his product. The quality elasticity of demand is no longer infinite, but a finite positive number. The quality elasticity of demand is larger to the extent that reputation functions in the market. Reputation means two things. A higher quality firm is more likely to experience repeat sales from its current customers. A higher quality firm is also more likely to receive new customers from the pool of customers dissatisfied with their current firm. Both factors mean that a higher quality firm will in the long run have a larger number of customers than a low quality firm.

A key characteristic of most of the professions in the service sector is that they tend to severely limit information flow 
to the consumers they service. An insightful study of this phenomenon describes it as follows.

Professions in the service sector exercise extensive control over. . . the type and amount of information publicly disseminated about these services. Professional codes of ethics usually prohibit advertising, limit brand name identification, strongly discourage public evaluation of other professionals' work, and place limitations wherever possible on other public indications of the characteristics, quality, or price of the services provided." (Benham and Benham, 1975.)

It is therefore important to know how such limitations on information flow might affect such markets. The analysis of this paper suggests that one effect of this limitation of information is to reduce the quality elasticity of demand. This in turn reduces the number of high quality firms and the number of consumers patronizing them. Three factors contribute to this result.

First, as people become better judges of the quality of services they receive, the quit rate of low quality firms relative to high quality firms becomes larger. That is, dissatisfied customers are more often justifiably dissatisfied. Second, customers searching for a new firm are more likely to choose a high quality firm as information in the market increases. Third, as information and consumer sophistication decrease, consumers become less able to supply one another with detalled descriptions of the quality of the firms they patronize. Word-of-mouth advertising becomes based more and more on simple positive or negative recommendations. In such a situation an externality is associated with the consumer's choice of a rule when to quit his current firm. His choice of rule affects other consumers through their reliance on his recommendation. The individually rational decision of how harsh a judge to be does not take this extra marginal benefit into account and consequently the consumer is a less harsh judge of his current firm than is socially optimal. This translates into a lower than optimal quality elasticity of demand.

The reward to producing high quality goods is more customers. The reward to producing low quality goods is lower costs and thus a higher profit per good. This latter factor becomes less important as market price rises above the average variable cost of producing high quality goods because the relative cost savings to producing low quality goods becomes smaller. In a zero profits entry equilibrium price rises above average variable cost as fixed costs grow. Therefore, ceteris paribus, industries which exhibit higher fixed costs should experience less problems with misrepresentation of quality. This suggests that barriers to entry established by professional associations which take the form of large fixed costs such as training requirements or license fees may well act to insure product quality, even in the absence of effective quality monitoring by the association. The magnitude of the incentive created is easily determined from cost data and could therefore be empirically investigated.

\section{THE DEPARTURE RATE AND ARRIVAL RATE}

Firms are assumed to be able to produce either high quality or low quality goods. Variables associated with high quality firms will be subscripted with an " $h "$; those associated with low quality firms will be subscripted with an " $\ell$ ". There are $N$ identical 
consumers, each consuming one unit of the good per period. Consumers can only identify the quality of the good they receive after purchasing it, and even then only probabilistically. After purchasing a high quality good, consumers mistakenly identify it as low quality with probability $\alpha$; after purchasing a low quality good, consumers mistakenly identify it as high quality with probability $\beta$. Assume that $\alpha+\beta<1$. This means that the consumer is more likely to believe that a good is of high quality if it is of high quality, than if it is of low quality. ${ }^{1}$

Let $\gamma_{h}$ be the random variable describing the observed quality of a good for a consumer patronizing a high quality good. Let $\gamma_{\ell}$ be the similar random variable for a consumer patronizing a low quality firm. Let $h$ denote observation of a high quality good and $l$ denote observation of a low quality good. Then $\gamma_{h}$ and $\gamma_{l}$ can be written as follows.

$$
\begin{aligned}
& r_{h}=\left\{\begin{array}{l}
h, \text { with probability } 1-\alpha \\
l, \text { with probability } \alpha
\end{array}\right. \\
& r_{\ell}=\left\{\begin{array}{l}
h, \text { with probability } \beta \\
\ell, \text { with probability } 1-\beta
\end{array}\right.
\end{aligned}
$$

Each consumer receives a new observation on the firm he is patronizing each period. This allows him to update his estimate of the probability that the firm he is patronizing is producing the high quality good. Let $\mathrm{p}_{h}^{\mathrm{t}}$ and $\mathrm{p}_{l}^{\mathrm{t}}$ be the random variables describing the consumer's estimate of his firm's quality after patronizing it for $t$ periods. At the end of the first period, the consumer's estimate depends only on that period's observation. Let the function $g_{1}$ describe the consumer's estimation process.

$$
\begin{aligned}
& p_{h}^{1}=g_{1}\left(\gamma_{h}\right) \\
& p_{l}^{1}=g_{1}\left(\gamma_{l}\right)
\end{aligned}
$$

Assume that the consumer estimates a higher probability that the firm is producing high quality goods if he observes a high quality good. Formally, assume that

$$
g_{1}(h) \geq g_{1}(\ell)
$$

For periods after the first period, the consumer updates his existing estimate. Let the set of functions $\left\{g_{t}\right\}_{t=2}^{\infty}$ describe this behavior

$$
\begin{aligned}
& p_{h}^{t}=g_{t}\left(p_{h}^{t-1}, \gamma_{h}\right) t=2,3, \ldots \\
& p_{l}^{t}=g_{t}\left(p_{l}^{t-1}, \gamma_{l}\right) t=2,3, \ldots
\end{aligned}
$$

As for $g_{1}$ assume that observations of high quality produce at least as large estimates. Formally, for any $p \in[0,1]$

$$
g_{t}(p, h) \geq g_{t}(p, l)
$$

Also, assume that a higher last period estimate results in at least as high an estimate this period. Formally, for $p, q \in[0,1]$ and $\mathrm{p}>\mathrm{q}$, then

and

$$
\begin{aligned}
& g_{t}(p, h) \geq g_{t}(q, h) \\
& g_{t}(p, l) \geq g_{t}(q, l) .
\end{aligned}
$$

The consumer chooses a time dependent reservation probability, $q(t)$, such that he quits his current firm and finds a new supplier if and only if his probability estimate at time $t$ falls below $q(t)$. 
Specific analysis of the nature of $q(t)$ is not important for this paper. (See the previously cited work on repeated games for some related work.) When the consumer leaves his current firm, he searches among the firms, using any information he can find from consumers and other sources. This process will be modelled in section IV. The consumer then begins consumption and quality estimation with the new firm he selects. Let $B_{h}^{\tau}$ and $B_{l}^{t}$ be the probabilities of the consumer spending at least $t$ periods with, respectively, a high and low quality firm. We can write

$$
\begin{aligned}
& \mathrm{B}_{h}^{\mathrm{t}}=\operatorname{Pr}\left\{\hat{i=1}_{i=1}^{\mathrm{t}}\left(\mathrm{P}_{h}^{i} \geq \mathrm{q}(i)\right)\right\} \\
& B_{l}^{t}=\operatorname{Pr}\left\{\stackrel{t}{\stackrel{A}{A}}\left(p_{l}^{i} \geq q(i)\right)\right\} .
\end{aligned}
$$

Now define the numbers $\mathrm{B}_{h}$ and $\mathrm{B}_{\ell}$.

$$
\begin{aligned}
& B_{h}=1+\sum_{t=1}^{\infty} B_{h}^{t} \\
& B_{\ell}=1+\sum_{t=1}^{\infty} B_{\ell}^{t} .
\end{aligned}
$$

In the context of this rather general structure, we can now draw a conclusion that will be used in the remainder of the paper. It turns out that if a fixed number of new consumers, $n$, choose a given firm every period, then in the long run the firm's expected number of consumers is $n / B_{h}$ or $n / B_{\ell}$, depending on whether it produces high or low quality goods. That is, in the long run, on average $1 / B_{h}$ or $1 / B_{l}$ of the firm's customers leave it every period. Let $\mathrm{d}_{h}$ and $\mathrm{d}_{l}$ denote these departure rates.

$$
\begin{aligned}
\mathrm{d}_{h} & =1 / \mathrm{B}_{h} \\
\mathrm{~d}_{\ell} & =1 / \mathrm{B}_{\ell}
\end{aligned}
$$

Furthermore $\mathrm{d}_{h}$ is at least as small as $\mathrm{d}_{\ell}$. That is, high quality firms experience a lower departure rate than low quality firms.

Proposition 1 summarizes this result.

\section{Proposition 1:}

(1) If $n$ new consumers arrive at a firm each period, in the long run the expected number of consumers is $n / B_{h}$ or $n / B_{l}$, depending upon whether the firm produces high or low quality goods. Therefore in the long run on average the fraction $d_{h}$ and $d_{\ell}$, respectively, of a high and low quality firm's customers leave it.

(2) $\mathrm{d}_{h} \leq \mathrm{d}_{\ell}$.

(3) $d_{h}$ is non decreasing in $(1-\alpha)$.

$\mathrm{d}_{\ell}$ is non decreasing in $(1-\theta)$.

Proof:

See Appendix.

Firms of the same quality have already been modelled as possessing the same departure rate. It is natural to assume that firms of the same quality also have the same number of new customers arriving on average. The number of arrivals per high quality firm should not necessarily equal the number of arrivals per low quality firm, however. Consumers can obtain some information about potential 
firms to patronize from other consumers or other sources of information such as government or consumer associations. Let $A_{h}$ and $A_{l}$ be the average number of consumers arriving at high and low quality firms, respectively. Let $G_{h}$ and $G_{\ell}$ be the number of high and low quality firms. Then let $a$ denote the ratio of arrivals, where $a$ is in $[1, \infty]$.

$$
a=\frac{\mathrm{A}_{h} / \mathrm{G}_{h}}{\mathrm{~A}_{\ell} / \mathrm{G}_{\ell}}
$$

If there were absolutely no information available, then $a$ would be 1 . Consumers would be equally likely to choose any firm. As information about firm quality becomes better, consumers become better able to differentiate between high and low quality firms, and a becomes larger. For the discussion in section VI, $a$ will be assumed to be created by a particular process. For the purposes of the other sections it can be any constant. 2

\section{EQUILIBRIUM FIRM SIZE}

Although many of the equilibrium quantities such as firm size are expected values, they will be spoken of as certain for ease of exposition. Firms reach a constant size when their number of arrivals equals their number of departures. This is defined as their equilibrium size. The conclusion of this section is that the higher number of arrivals and lower departure rate for high quality firms results in the equilibrium size of high quality firms being larger than the equilibrium size of low quality firms.

Let $\mathrm{N}_{h}$ and $\mathrm{N}_{\ell}$ be the number of consumers in high and low quality firms. Let $\mathrm{D}_{h}$ and $\mathrm{D}_{l}$ be the number of consumers departing from high and low quality firms. Then by definition

$$
\begin{aligned}
& \mathrm{D}_{h}=\mathrm{d}_{h} \mathrm{~N}_{h} . \\
& \mathrm{D}_{\ell}=\mathrm{d}_{\ell} \mathrm{N}_{l} .
\end{aligned}
$$

Finally, by (17)

$$
\frac{A_{h}}{A_{\ell}}=\frac{G_{h}}{G_{\ell}} a .
$$

The above three equations describe the structure of consumer flows in the system. Consumers leave high and low quality firms at the rates of $\mathrm{d}_{h}$ and $\mathrm{d}_{\ell}$. The ratio of arrivals at high and low quality firms is described by (20). In equilibrium, since firm size is constant, arrivals equal departures. That is, our equilibrium conditions are

$$
\begin{aligned}
& \mathrm{A}_{h}=\mathrm{D}_{h} \\
& \mathrm{~A}_{l}=\mathrm{D}_{l} .
\end{aligned}
$$

Substitute (18) and (19) into (20) by using the equilibrium conditions to yield

$$
\frac{\mathrm{N}_{h} / \mathrm{G}_{h}}{\mathrm{~N}_{\ell} / \mathrm{G}_{\ell}}=\frac{\mathrm{d}_{\ell}}{\mathrm{d}_{h}}
$$

Let $x_{h}$ and $x_{l}$ denote the size of high and low quality firms and $\gamma$ denote $a_{\ell} / d_{h}$. Then (23) is

$$
\frac{x_{h}}{x_{l}}=\gamma
$$

The relative size of high and low quality firms depends on the parameter $\gamma$. How can $\gamma$ be interpreted? It becomes larger as the 
relative number of arrivals begins to favor high quality firms (a goes up) or the relative departure rate favors high quality firms ( $d_{h}$ goes down relative to $d_{\ell}$ ) Therefore $\gamma$ is a composite measure of the extent to which arrivals and departures reward high quality firms relative to low quality firms. The parameter $\gamma$ is always in $[1, \infty]$. When $\gamma$ equals 1 consumer arrivals and departures do not discriminate between high and low quality firms. As $\gamma$ grows larger, high quality firms begin to experience more arrivals and fewer departures than low quality firms. This results in a larger size for high quality firms relative to low quality firms.

One final assumption is that all firms face a capacity

constraint of $k$. Therefore in equilibrium

$$
x_{h}=k \text {. }
$$

The single market price adjusts so that the high quality firms produce at capacity. Low quality firms masquerading as high quality firms necessarily produce at less than capacity given that they sell at the same price. An equilibrium in which all low quality firms charged a lower price and also produced at capacity would no longer involve misrepresentation of product quality, since consumers could use price to differentiate between product quality prior to purchase. Some firms may well choose to produce a lower quality product at a lower price. However, this amounts to the firm exiting the market for high quality goods and entering a different market. In this paper I study the single market for high quality goods and incentives for misrepresentation within it. The question of how markets for various qualities relate to one another and how relative prices equilibrate is a separate problem. Understanding the behavior within each market is the first step towards dealing with this larger problem.

IV FIRM ENTRY AND PRODUCT QUALITY CHOICE

At the market price, $\mathrm{p}$, every firm must decide whether to actually produce a high quality product, to produce a low quality product and misrepresent its quality, or to not produce at all. Assume that there is a total of I firms, indexed by $i$. Let $c_{h}^{i}$ and $c_{l}^{i}$ be the constant marginal cost for firm $i$ of producing, respectively, high and low quality units. Let $F+F_{i}$ be the fixed cost of production for firm $i .^{3}$

When firms compare the relative profitability of these three courses of action, they assume that any action on their pari will leave average firm size for high and low quality firms and other firms' behavior unaffected. It is also assumed that firms are concerned with maximizing their long run average profits. In other words, firms do not discount future profits. ${ }^{4}$ This assumption allows analysis of the long run incentives to misrepresent product quality as opposed to the incentives for "fly by night" operators. This latter problem has been analyzed by others (Klein and Leffler, 1979).

The long run average profits to be accrued from producing the high quality good, $\Pi_{h}^{i}$, are

$$
\pi_{h}^{i}=p x_{h}-c x_{h}^{i} x_{h}-F-F_{i}
$$

and from producing the low quality good are

$$
\pi_{l}^{i}=p x_{l}-c_{l}^{i} x_{l}-F-F_{i} .
$$


The f1rm chooses the course of action associated with the largest of the two numbers $\Pi_{h}^{1}$ and $\Pi_{\ell}^{i}$. By rearranging (26) and (27),

$$
\pi_{h}^{i} \geq \Pi_{l}^{i} \Leftrightarrow \frac{p-c_{h}^{i}}{p-c_{l}^{1}} \geq \frac{x_{l}}{x_{h}} .
$$

Rearrange to yield

$$
\pi_{h}^{i} \geq \pi_{l}^{i} \Leftrightarrow P \geq \frac{x_{h} c_{h}^{i}-x_{l} c_{l}^{i}}{x_{h}-x_{l}} .
$$

Let $p_{i}^{*}$ be defined by

$$
\mathrm{p}_{i}^{*}=\frac{\mathrm{x}_{h} c_{h}^{i}-x_{\ell} c_{l}^{i}}{x_{h}-x_{\ell}} .
$$

In accord with Klein and Leffler (1979), call $\mathrm{p}_{i}^{*}$ the quality guaranteeing price for firm $i$. At prices above $p_{1}^{*}$ firm $i$ produces high quality goods, while at prices below $\mathrm{P}_{i}^{*}$ it produces low quality goods. As a convention, assume the firm produces high quality goods when the market price is $P_{1}^{*}$ as well. It is easy to see that $p_{1}^{*}$ is greater than $c_{h}^{i}$ from (29) so long as $x_{h}>x_{l}$.

The intuition behind this result is clear. Since fixed costs are the same for either mode of production, only variable costs are relevant in a comparison. If price equalled the variable cost of producing high quality, then there would be no advantage to generating more business by producing high quality goods. It would be more profitable to sell fewer goods, but make a profit on each, As price rises above $c_{h}^{1}$, the advantage to generating more business by producing high quality goods becomes more substantial until finally at some point it becomes large enough that producing high quality goods becomes the most profitable course of action.

Note that there is no necessary relation between how high cost a firm is and whether it is more inclined towards producing high or low quality goods without further assumptions. Suppose that we can order the firms so that $c_{h}^{i}$ and $c_{l}^{i}$ both increase in $i$. Even in this case $p_{i}^{*}$ may not increase in $i$. However, if we additionally assume that $c_{h}^{i}$ increases in $i$ more quickly than $c_{l}^{i}$, then $p_{i}^{*}$ increases in $i$. In particular, this includes the case where $c_{h}^{i} / c_{l}^{i}$ is a constant. Therefore under a fairly plausible assumption, higher cost firms are more likely than lower cost firms to produce lower quality goods.

Two points concerning the firms quality choice in long run equilibrium should be noted. First, in equilibrium $x_{h} / x_{l}=\gamma$, so as $\gamma$ becomes larger, the quality guaranteeing price becomes smaller. Reputation affects firm size through two processes in this model. A firm producing high quality goods experiences a lower departure rate and a higher arrival rate. The number $\gamma$ is a measure of the combined strength of these two factors. As $\gamma$ becomes larger, reputation matters more and a firm is more likely to produce high quality products.

Second, a "perfectly efficient" leave rate or arrival rate would solve the problem by itself. That is, if $\mathrm{d}_{h} / \mathrm{d} l$ was 0 or $a$ was $\infty$, then $\mathrm{p}^{*}$ would be 0 and all prices above $c_{h}^{i}$ would induce production of high quaiity goods. Therefore the fact that consumers cannot determine the quality of a good prior to purchase does not in and of itself create a market with low quality goods if firms have sufficiently low discount rates for future business. Difficulty in determining 
the quality of a good even after purchase adds an entirely new reason to expect production of low quality goods. A firm may have an incentive to produce low quality goods even in the presence of no discounting when such post-purchase observability problems exist.

Firm $i$ therefore makes its production decision as follows. 5

$$
\begin{array}{ll}
x_{h}, x_{\ell} \text { and } p \text { are } & \text { Firm } i \text { 's decision } \\
\text { such that } & \\
\Pi_{h}^{i} \geq \Pi_{l}^{i} \wedge \Pi_{h}^{i} \geq 0 & \text { Produce high quality } \\
\Pi_{l}^{i}>\Pi_{h}^{i} \wedge \Pi_{l}^{i} \geq 0 & \text { Produce low quality } \\
\Pi_{h}^{i}<0 \wedge \cdot \Pi_{l}^{i}<0 & \text { Do not produce }
\end{array}
$$

Therefore the number of high and low quality firms is determined as follows. Let 非 denote the number of elements in the set $\mathrm{S}$.

$$
\begin{aligned}
& G_{h}=\left\{\left\{i: \Pi_{h}^{i} \geq \Pi_{l}^{i} \wedge \Pi_{h}^{i} \geq 0\right\}\right. \\
& G_{l}=\#\left\{i: \Pi_{l}^{i}>\Pi_{h}^{i} \wedge \Pi_{l}^{i} \geq 0\right\} \\
& G=G_{h}+G_{l}
\end{aligned}
$$

\section{MARRET EQUILIBRIUM}

Equations (23), (25), (31), and (32) together with the fact that there are $\mathrm{N}$ consumers, determine market equilibrium. For convenience, I rewrite them here.

$$
\begin{aligned}
& \frac{\mathrm{N}_{h} / \mathrm{G}_{h}}{\mathrm{~N}_{\ell} / \mathrm{G}_{\ell}}=\gamma \\
& \mathrm{N}_{h} / \mathrm{G}_{h}=\mathrm{k} \\
& \left.G_{h}=\#_{i}: \frac{p-c_{h}^{i}}{p-c_{l}^{i}} \geq \frac{N_{h} / G_{h}}{N_{l} / G_{l}} \wedge\left(p-c_{h}^{i}\right) \frac{N_{h}}{G_{h}} \geq F+F_{i}\right\} \\
& \left.G_{l}=\#_{\{i}: \frac{p-c_{h}^{i}}{p-c_{l}^{i}}<\frac{N_{h} / G_{h}}{N_{l} / G_{l}} \wedge\left(p-c_{l}^{i}\right) \frac{N_{l}}{G_{l}} \geq F+F_{i}\right\} \\
& \mathrm{N}_{h}+\mathrm{N}_{l}=\mathrm{N}
\end{aligned}
$$

These five equations determine the five variables $\mathrm{N}_{h}, \mathrm{~N}_{\ell}, G_{h}, G_{\ell}$ and p. I assume that a solution exists to the above.

To derive comparative statics it is convenient to rewrite these five equations as follows:

$$
\begin{aligned}
\mathrm{N}_{h}-\mathrm{kG} h & =0 \\
\mathrm{~N}_{\ell}-(\mathrm{k} / \mathrm{\gamma}) G_{\ell} & =0 \\
\mathrm{~N}_{h}+\mathrm{N}_{\ell}-\mathrm{N} & =0 \\
\mathrm{G}_{h}-\mathrm{f}_{h}(\mathrm{p}, \mathrm{F}, \mathrm{k}, \gamma) & =0 \\
\mathrm{G}_{h}-\mathrm{f}_{\ell}(\mathrm{p}, \mathrm{F}, \mathrm{k}, \gamma) & =0
\end{aligned}
$$

where $f_{h}$ and $f_{\ell}$ are defined by

$$
\begin{aligned}
f_{h}(p, F, k, \gamma)-\#\left\{i: \frac{p-c_{h}^{i}}{p-c^{i}} \geq \frac{1}{\gamma} \wedge\left(p-c_{h}^{i}\right) k \geq F+F_{i}\right\} \\
\text { and } \quad f_{\ell}(p, F, k, \gamma)=\#\left\{i: \frac{p-c_{h}^{i}}{p-c_{l}^{i}}<\frac{1}{\gamma} \wedge\left(p-c_{\ell}^{1}\right) \frac{k}{\gamma} \geq F+F_{i}\right\}
\end{aligned}
$$


Since $f_{h}$ and $f_{l}$ only assume integer values they are not differentiable. Therefore it is not strictly correct to apply the algorithm of total differentiation to obtain comparative statics results. However, we can perform exactly the same algorithm for small discrete changes of the parameters. To avoid the extra notational complexdty of this procedure, I will formally use differential notation and apply the total differentiation algorithm. However, strictly speaking some of the infinite differences should actually be interpreted as small discrete changes.

Some properties of $f_{h}$ and $f_{\ell}$ are useful in deriving comparative statics results. For reference, they are gathered together in Proposition 2.

\section{Proposition 2:}

(1) $f_{h}$ is non decreasing in $\{\mathrm{p}, \gamma, \mathrm{k}\}$

(2) $f_{h}$ is non increasing in $\{F\}$

(3) $\mathrm{f}_{\ell}$ is non decreasing in $\{\mathrm{k}\}$

(4) $f_{h}$ is non increasing in $\{F, \gamma\}$

(5) $\left(f_{h}+f_{\ell}\right)$ is non decreasing in $\{k, p\}$

(6) $\left(f_{h}+f_{\ell}\right)$ is non increasing in $\{\gamma, F\}$

\section{Proof:}

Obvious.

The comparative statics results are now stated in Proposition 3.
Proposition 3:

(1) Effects of $\gamma$ :

(i) $N_{h}$ and $G_{h}$ are non decreasing in $\gamma$.

(ii) $\mathrm{N}_{\ell}$ is non increasing in $\gamma$.

(iii) The effect of $\gamma$ on $p$ and $G_{\ell}$ is indeterminate.

(2) Effects of F:

Suppose that $\mathrm{f}_{\ell \mathrm{P}} \leq \frac{\mathrm{f}_{\ell \mathrm{F}} \mathrm{f}_{h \mathrm{p}}}{\mathrm{f}_{h \mathrm{~F}}}$.

Then

(i) $N_{h}$ and $G_{h}$ are non decreasing (non increasing) in $F$.

(ii) $\mathrm{N}_{\ell}$ and $G_{\ell}$ are non increasing (non decreasing) in $\mathrm{F}$.

As well it is always true that

(iii) $\mathrm{P}$ is non decreasing in $\mathrm{F}$.

(3) Effects of $k$ :

(i) $\quad \mathrm{p}$ is non increasing in $\mathrm{k}$.

(ii) The effects of $\mathrm{k}$ on $\mathrm{N}_{h}, \mathrm{G}_{h}, \mathrm{~N}_{\ell}$, and $G_{\ell}$ are indeterminate.

(r) Effects of $\mathrm{N}$ :

(i) $\mathrm{N}_{h}$ and $G_{h}$ are non decreasing in $\mathrm{N}$

(ii) The effect of $\mathrm{N}$ on $\mathrm{N}_{\ell}$ and $\mathrm{G}_{\ell}$ is indeterminate.

(iii) $\mathrm{p}$ is non decreasing in $\mathrm{N}$.

Proof: 


\section{Corollary 3-a:}

(i) $\mathrm{N}_{h}$ is non increasing in $\alpha$ and $\beta$.

$\mathrm{N}_{\ell}$ is non decreasing in $\alpha$ and $\beta$.

(ii) $\mathrm{N}_{h}$ is non decreasing in $\alpha$.

$\mathrm{N}_{\ell}$ is non increasing in $\alpha$.

\section{Proof:}

(i) This follows from Proposition 3 - (1) and Proposition 1 - (3) and the definition of $\gamma$.

(ii) This follows from Proposition $3-$ (1) and the definition of $\gamma$.

These comparative statics can be best understood by first recasting (34) - (38) in a more traditional "supply equals demand" framework. The demand is $\mathrm{N}$ and is fixed. Supply is the number of high quality firms, $G_{h}$, times the size of high quality firms, $k$, plus the number of low quality firms, $G_{\ell}$, times the size of low quality firms, $k / \gamma$. Long run equilibrium supply is thus $k G_{h}+(k / \gamma) G_{\ell}$. Market equilibrium occurs when

$$
N=k f_{h}(p, F, k, \gamma)+\frac{k_{f}}{\gamma} \ell(p, F, k, \gamma) .
$$

It is equation (46) that determines market price. Then $G_{h}, G_{\ell}, N_{h}$ and $\mathrm{N}_{0}$ are determined by

$$
\begin{aligned}
& \mathrm{N}_{h}=\mathrm{kf}_{h}(\mathrm{p}, \mathrm{F}, \mathrm{k}, \gamma) \\
& \mathrm{N}_{\ell}=\frac{\mathrm{k}_{\mathrm{f}}}{\gamma} \mathrm{f}_{\ell}(\mathrm{p}, \mathrm{F}, \mathrm{k}, \gamma) \\
& \mathrm{G}_{h}=\mathrm{f}_{h}(\mathrm{p}, \mathrm{F}, \mathrm{k}, \gamma) \\
& \mathrm{G}_{\ell}=\mathrm{f}_{\ell}(\mathrm{p}, \mathrm{F}, \mathrm{k}, \gamma) .
\end{aligned}
$$

Therefore, the effect of any parameter on price is determined solely by (46). The effect of any parameter on the other variables, $N_{h}$, $\mathrm{N}_{\ell}, \mathrm{G}_{h}$, or $\mathrm{G}_{\ell}$, is determined by two factors -- first, its effect on price and price's subsequent effect on the other variable and, second, the direct effect of the parameter on the variable -- through the appropriate equation of (47) - (50). For example, we can write, based on (47)

$$
\frac{\partial N_{h}}{\partial E}=k \frac{\partial f_{h}}{\partial p} \frac{\partial p}{\partial F}+\frac{k \partial f_{h}}{\partial F}
$$

The effect of $\mathrm{F}$ on equilibrium price is $\partial \mathrm{p} / \partial \mathrm{F}$ as determined by (46). Then $k\left(\partial \mathrm{f}_{h} / \partial \mathrm{p}\right)$ measures the effect of price on $\mathrm{N}_{h}$. Finally, $k\left(\partial \mathrm{f}_{h} / \partial \mathrm{F}\right)$ measures the direct effect of $\mathrm{F}$ on $\mathrm{N}_{h}$

\section{Effects of $\gamma:$}

The effect of an increase of $\gamma$ on supply is ambiguous.

When $\gamma$ increases, $f_{h}$ increases and $f_{l}$ decreases. The total number of firms, $f_{h}+f_{\ell}$, decreases, but because more of them are the larger high quality firms, it is not clear whether $\mathrm{kf}_{h}+(\mathrm{k} / \gamma) \mathrm{f}_{\ell}$ decreases or increases. Therefore the effect of $\gamma$ on equilibrium price is also ambiguous. If $\gamma$ increases supply, it decreases price; if $\gamma$ decreases supply it increases price. ${ }^{6}$

Now consider the effect of $\gamma$ on the other four variables. We can divide the effect, coneeptually, into two parts: the direct effect of $\gamma$ on the variable and the indirect effect through changes in the equilibrium value of price. First consider the direct effect -assume that price is constant. Now consider the number of firms, $G_{h}$ 
and $G_{\ell}$. The fact that $\gamma$ goes up means that the relative size of high quality firms increases. Therefore every firm in the market finds it relatively more profitable to produce high quality goods and some firms which formerly produced low quality goods instead now produce high quality goods. Also, some firms which formerly found it profitable to be in the market as low quality producers now may find it unprofitable to be in the market at all. That is, when $\gamma$ rises, the long run effect is to lower the size of low quality firms in absolute terms as well as relative to the size of high quality firms. Therefore some low quality firms may either begin producing high quality goods or leave the market entirely.

Now consider the direct effect of $\gamma$ on $\mathrm{N}_{h}$ and $\mathrm{N}_{\ell}$ (i.e., still assume that $p$ is constant.) Even if $G_{h}$ and $G_{l}$ remained constant, an increase in $\gamma$ means that both relative arrival and departure rates favor high quality firms more and therefore the relative size of high quality firms increases. This means that $\mathrm{N}_{h}$ increases and $\mathrm{N}_{l}$ decreases. The fact that $G_{h}$ also goes up and $G_{l}$ goes down amplifies this change. But $P$ changes as well, to satisfy the equilibrium condition that supply equal demand. It can be shown that the indirect effects do not overwhelm the direct effects for $\mathrm{N}_{h}, \mathrm{G}_{h}$ and $\mathrm{N}_{l}$; the effect on $G_{\ell}$ may be reversed. However, the equilibrium values of $\mathrm{N}_{h}$ and $\mathrm{N}_{\ell}$ are probably of most interest since these are the number of high and low quality goods sold. Proposition 3 therefore states that when $\gamma$ increases, the number of high quality units being sold increases and the number of low quality units being sold decreases. Recall that $\gamma$ is a measure of the extent to which reputation operates in the market.
Reputation includes two phenomena: the tendency for a higher quality firm to receive more repeat purchases and the tendency for a higher quality firm to receive more new arrivals through word-of-mouth advertising. Both operate to affect relative firm size and $\gamma$ measures their joint effect.

From Corollary 3-a, improving the consumer's ability to judge the quality of products and providing more information about the quality of all firms will, through their effect on $\gamma$, increase $\mathrm{N}_{h}$ and decrease $\mathrm{N}_{\ell}$. To the extent that advertising improves consumers' ability to judge and compare quality and to select new high quality firms, it should therefore result in a larger fraction of high quality products.

\section{Effects of $\mathrm{F}$ :}

The effect of an increase in the fixed costs of all firms on price is determinate. An increase in fixed costs does not change the relative profitability of high and low quality production, but it does make production in general less profitable. Therefore, the long run supply decreases and equilibrium price increases.

Now consider the effect of increasing $F$ on the other four variables. The direct effect is to decrease all four, since firms of both types leave the industry. However, price then rises to bring supply back up to $\mathrm{N}$ and this also influences the four variables. The net effect on the number of each type of firm is therefore the sum of the effect from lowering $F$ and then raising $P$ so that total supply remains unchanged. 
As price rises, all firms find production of high quality goods becoming more profitable relative to low quality goods. Therefore some existing firms in the market switch from production of low quality to high quality goods. However, because price rises there is an entry of firms producing both high and low quality goods. If this second factor is large enough, it is conceivable that as price goes up, the number of low quality firms as well as the number of high quality firms increases.

Suppose, for a moment, that this is not the case -- that the number of low quality firms decreases when price rises. Then the net effect of $F$ is easy to sign. Raising $F$ directly causes both $G_{h}$ and $G_{\ell}$ to drop. Then the compensating price rise causes further drops in $G_{\ell}$; however production returns to its original level and firm size is unchanged. Therefore $G_{h}$ must have risen above its original level. In this case, an increase in fixed costs causes an increase in the number of high quality firms and a decrease in the number of low quality firms. Since $F$ does not affect firm size, an increase in the number of consumers patronizing high quality firms and a decrease in the number of consumers patronizing low quality firms also results.

Even if a price rise causes an increase in the number of low quality firms, the above result will still hold as long as an increase in price does not cause $G_{\ell}$ to rise "too much." The initial increase in $F$ causes both $G_{\ell}$ and $G_{h}$ to drop. The equilibrium adjustment of price upward then causes $G_{\ell}$ and $G_{h}$ to both rise. So long as the relative rise in $G_{\ell}$ is exceeded by the relative rise in $G_{h}$, the result still holds. That is, when $f_{\ell_{p}}$ is positive we must have

$$
\left|\frac{f_{\ell_{P}}}{f_{\ell_{F}}}\right| \leq\left|\frac{f_{h_{P}}}{f_{h_{F}}}\right|
$$

for an increase in $F$ to cause an increase in the equilibrium values of $\mathrm{G}_{h}$ and $\mathrm{N}_{h}$ and a decrease in the equilibrium values of $G_{\ell}$ and $\mathrm{N}_{\ell}$. This condition is fairly plausible. For example suppose that entry and exit into the industry occur by low quality firms. That is, hfgh quality firms are also the low cost, high profit firms. Section IV discussed conditions under which this might occur. Then $\mathrm{f}_{h \mathrm{~F}}=0$ but $\mathrm{f}_{h \mathrm{p}}$ is positive due to "switchovers" by existing firms and the RHS of (52) is $\infty$. However, the reverse results may hold if an industry is such that low profit firms tend to be high quality producers and price rises cause very few switchovers from low to high quality but do cause entry of low quality firms.

This analysis suggests that industry organizations may well promote product quality even if they engage in little or ineffective quality monitoring. To the extent that they create large fixed costs for members by requiring training or license fees, production of high quality goods becomes more attractive to members. Furthermore, to the extent that the organization is able to act like a monopolist, it will restrict entry and raise prices, which once again creates an indirect incentive to produce high quality goods. This is not to suggest that anti-competitive trade associations are necessarily social benefactors. It may well be that the social costs of such anticompetitive actions outweigh the benefits of improved product quality. This is an empirical issue. The magnitude of the incentive for firms 
to produce high quality goods created by license fees or training costs for various industries is readily determinable from cost data. It would be interesting to determine if industry association requirements actually tend to substantially alter members' incentives or rather merely create opportunity for monopoly profits.

\section{Effects of k:}

Most effects of changing capacity are indeterminate. When capacity is increased, long run supply shifts out so equilibrium price drops.

\section{Effects of $N$ :}

When the number of consumers increases, equilibrium price of course rises. The effect of $\mathrm{N}$ on the other four variables $\mathrm{N}_{h}, \mathrm{~N}_{\ell}, \mathrm{G}_{h}, \mathrm{G}_{\ell}-$ is totally through the effect of increasing price. Therefore the number of high quality firms and the number of consumers patronizing high quality firms increases. The effect of price on the number of low quality firms is indeterminate for reasons previously discussed.

VI CHOICE OF A RESERVATION PROBABILITY

The consumer must decide how harsh a judge to be of his current firm when contemplating switching firms. The consumer would like to select some rule which tends to maximize his long run probability of patronizing a high quality firm. This goal is complicated by another factor -- search is costly. Therefore, the consumer might choose a rule involving less search than that which maximizes his probability of patronizing a high quality firm in order to save on search costs.

A more specific assumption about the process of consumer search for new firms is introduced in this section. Assume that consumers receive incomplete information from their friends and associates about the firms they patronize. In particular, consumers receive a judgment that the firm is either high quality or low quality as opposed to a detailed description of the friend's experience with a particular firm. A consumer can recomnend either for or against his current firm when a fellow consumer makes an inquiry. He recommends for it if he intends to patronize it again next period. He recommends against it if he intends to switch himself.

This assumption probably becomes more reasonable when quality has many dimensions and is not easily summarized by any statistic. For example, the quality of a doctor involves a range of poorly measurable factors such as his diagnostic judgment, surgical competence, bedside manner, etc. The quality of many professional services has a number of dimensions. It may well be that in such a case the most often communicated piece of information is simply whether the firm is "good" or "bad."

One other necessary condition for this assumption to be reasonable is that consumers be relatively homogeneous, or at least that consumers be able to easily classify other consumers as to whether their tastes are similar. In the extreme case, we could imagine a case where quality consists of a number of different factors valued differently by different consumers. Firms are "stochastically 
identical" -- the fact that one consumer prefers firm 1 to firm 2 gives us no information about any other consumer's preferences. In this case, a positive or negative quality recommendation provides no information at all. 8

The interest in analyzing this class of markets, as opposed to those where all available information is perfectly communicated, lies in the fact that an externality exists in the consumer's choice of how harsh a judge to be. When the consumer chooses a reservation probability he has an effect on those consumers who will use his judgment as a basis upon which to select a new firm. However, he does not take this into account when choosing a reservation probability. That is, there is an extra marginal benefit to choosing a higher reservation probability that the consumer ignores -- the benefit that other consumers receive from more reliable judgments. As a consequence the individually rational choice of a reservation probability is lower than the socially rational choice.

To demonstrate the externality formally, assume that each consumer uses the following sort of rule for deciding when to leave a firm he patronizes. He chooses a reservation probability, q.9 The consumer continues to patronize the same firm until his estimate of the probability that the firm is high quality drops below $q$. Then he seeks out a new firm, possibly asking friends for recommendations. Recommendations are merely positive or negative. No actual probability estimate is communicated.

Consistent with the long run equilibrium orientation of this paper, we define an optimal reservation probability as the one which maximizes the consumer's long run average expected value. To define the socially and individually rational reservation probability some notation must be introduced. We will consider a particular consumer and label all variables associated with him with a "*". Variables for the other consumers will be identical and denoted by the variable without a "*." We will define a function $W(q *, q)$ which yields the long run expected value to the particular consumer if he chooses $q^{*}$ and everyone else chooses q. The particular consumer chooses an individually rational value of $q^{*}$. Let $Q(q)$ denote the particular consumer's choice of $q^{*}$ given that everyone else chooses $q$. Then $Q(q)$ satisfies

$$
W(Q(q), q) \geq \underset{\theta \varepsilon[0,1]}{\max } W(\theta, q)
$$

However, the particular consumer was chosen arbitrarily and consumers are alike. Therefore, the value of $\mathrm{q}$ that consumers choose satisfies

$$
\mathrm{q}=\mathrm{Q}(\mathrm{q})
$$

The optimal level of $\mathrm{q}$ is the one such that the return to each consumer is maximized. That is, the optimal level of q satisfies

$$
W(q, q) \geq \max _{\theta \varepsilon[0,1]} W(\theta, \theta) .
$$

The purpose of this section is to show that values of $q$ which satisfy (54) are different, and in general smaller than, values of $q$ which satisfy (55).

To do this, W must be defined. The departure rates for any consumer are a function of his choice of a reservation probability. Therefore we can write for some functions $\xi_{h}$ and $\xi_{l}$ : 


$$
\begin{aligned}
& \mathrm{d}_{h}=\xi_{h}(\mathrm{q}) \\
& \mathrm{d}_{l}=\xi_{l}(\mathrm{q}) \\
& \mathrm{d}_{h}^{*}=\xi_{h}\left(\mathrm{q}^{*}\right) \\
& \mathrm{d}_{\ell}^{*}=\xi_{l}\left(\mathrm{q}^{*}\right)
\end{aligned}
$$

A crucial realization for the purposes of this section is that the relative arrival rate for the particular consumer, $a^{*}$, depends on $d_{h}$ and $\mathrm{d}_{\ell}$ but not $\mathrm{d}_{h}^{*}$ or $\mathrm{d}_{\ell}$. The consumer's choice about which firm to patronize next period, given that he has left his old firm, depends on what other consumers tell him about whether they intend to patronize their firms next period. This latter fact depends on $\mathrm{d}_{h}$ and $\mathrm{d}_{\ell}$. Therefore so does $a^{\star}$. By composition with (56), $a^{\star}$ is a function of $q$ but not $q^{*}$. Therefore we can write for some function, $\delta$,

$$
a^{*}=\delta(q) \text {. }
$$

An example may make this point clearer: Suppose that the consumer considers a firm by asking one of its patrons for a recommendation and accepts a firm as soon as he receives a positive recommendation.

Suppose, as well, that the consumer has an equal chance of considering any firm. Then $a *$ is $1-\mathrm{d}_{h} / 1-\mathrm{d}_{\ell}$.

Costs of search for the consumer rise along with $q^{*}$ since

a large reservation probability means the consumer will be departing from firms more often and thus searching more often. Let $S\left(q^{*}\right)$ be the consumer's search costs. Let $u_{h}$ and $u_{l}$ be, respectively, the value of a high and low quality product to every consumer. The consumer now knows everything necessary to calculate an optimal reservation probability, except the long run probabilities of his patronizing a high quality firm or a low quality firm. Let $h$ * and $\ell^{*}$ denote these quantities.

Lemana 1:

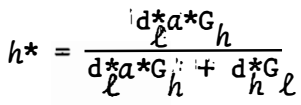

$$
\begin{aligned}
& l^{*}=\frac{d{ }_{h}^{*}\left(1-G_{h}\right)}{d_{l}^{*} a^{*} G+d_{h}^{*} G}
\end{aligned}
$$

Proof:

See Appendix.

From Section $V, G_{h}$ and $G_{l}$ are generally functions of $\gamma$ and thus of $q$ and $q^{*}$. When $G_{h}$ and $G_{l}$ vary with the consumers' choice of $q$ other externalities than the one identified at the start of this section could be identified based on the fact that the consumer does not consider the benefit that accrues to others when he generates a higher $G_{h}$ through search. However, this is a more standard argument. The externality originating because recommendations as opposed to objective quality information are communicated seems more novel and is thus the one I consider. To avoid confusing this argument with externalities involved with $G_{h}$ and $G_{\ell}, I$ assume $G_{h}$ and $G_{\ell}$ are constant. 10 Therefore $h *$ is a function of $q$ and $q *$ because $d \hbar$ and $\mathrm{d}_{\ell}^{*}$ depend on $\mathrm{q}^{*}$ through (56) and because $a^{*}$ depends on $\mathrm{q}$ through (57). Therefore we can write for some function, $\theta$, 


$$
h^{*}=\theta\left(q^{*}, q\right)
$$

Now $W\left(q^{*}, q\right)$ can be defined.

$$
W\left(q^{*}, q\right)=\theta\left(q^{*}, q\right) u_{h}+\left(1-\theta\left(q^{*}, q\right)\right) u_{l}-s\left(q^{*}\right) .
$$

Assume that $W\left(q^{*}, q\right)$ is concave and differentiable in $q^{*}$ and that $\mathrm{W}(\mathrm{q}, \mathrm{q})$ is concave and differentiable in $\mathrm{q}$. We can now state the conclusion of this section.

\section{Proposition 4:}

Let $\mathrm{x}$ satisfy (54) and $\mathrm{y}$ satisfy (55). Then $\mathrm{x} \neq \mathrm{y}$ so long as $\theta_{2}(x, x) \neq 0$. Furthermore, if $\theta_{2}(q, q)>0$ for every $q$, then $x<y$.

Proof:

See Appendix.

When the individual chooses a reservation probability, he does not consider the benefit he confers on others through providing recommendations. That is, he ignores $\theta_{2}(q, q)$. Therefore so long as this benefit is non zero, he will in general make the wrong choice. It might be most reasonable to expect the relative arrival rate, $\beta$, to always grow with q. Then $\theta_{2}$ is positive. This means that as consumers become harsher critics of firm performance they become relatively better at differentiating high quality firms from low quality firms. If this is the case, then the socially rational reservation probability is larger than the individually rational probability. When the individual chooses a reservation probability, he does not consider the benefit he confers on others through providing recommendations, and thus chooses too low a level. If $\theta_{2}$ exhibits perverse behavior and becomes negative at some point, then the consumer may well be ignoring a negative externality and consequently choose $q^{*}$ too high. In either case, an externality exists which precludes achievement of a decentralized social optimum. of course this externality becomes smaller to the extent that consumers are able to communicate the actual estimated quality of their firm, as opposed to a positive or negative recommendation. This analysis therefore reinforces the policy recommendations of Wilde and Schwartz (1979), although for entirely different reasons.

This suggests that the state should reduce the costs to consumers of comparing purchase alternatives. One way to achieve this is for the state to require more standardization of the way in which firms quote prices and terms because such standardization would reduce the cost of comparison shopping. It also seems wise to remove barriers to private, voluntary standardization. Thus courts should not regard the use by a seller of a' standard form contract as a factor which militates against enforcement of the contract, for such judicial conduct raises the cost to firms of creating standardized forms. Also, legislatures should consider relaxing antitrust enforcement to permit more voluntary standardization of the ways in which prices and terms are quoted.

Also, to the extent that advertising generally increases the sophistication and awareness of all consumers, it may facilitate transfer of information among consumers. 
When consumers have difficulty in accurately evaluating the quality of a good or service, firms may contemplate staying in the market over the long run even though they misrepresent quality. "Reputation" provides an incentive for firms to produce high quality items. Through differential quit and arrival rates, higher quality firms tend to have more customers. The model seems to apply particularly well to professional services. Professional associations tend to severely limit information flow to the consumers they service. Three different factors suggest that this lowers the quality elasticity of demand and thus results in higher fractions of low quality firms and consumers patronizing them. One of the three factors depends on the observation that when transaction costs severely limit word-ofmouth advertising an externality begins to be attached to the consumer's choice of whether or not to continue patronizing a firm. I believe this idea is new to the literature.

The formal model in this paper resembles in some respect and was influenced by that of Schmalensee (1978), in which he investigates the relationship between advertising and product quality. Product quality is fixed in this model and advertising is the choice variable of the firms. It is natural to ask if Schmalansee's results are robust to the case where firms may also choose product quality as in this paper's model. I am currently working on this extension. The other, more difficult, direction for research suggested by this paper concerns the relationship between price dispersion and product quality. This paper assumes that a single market price exists. Presumably another reward for establishing a reputation might be the ability to charge a higher price.

\section{Proposition 1:}

(1) Consider a high quality firm's population of customers. There are $n$ customers who just arrived. There are an average of $B_{h^{1}}$ customers who have been with the firm one period before. In general there are an average of $\mathrm{B}^{\mathrm{t}} \mathrm{n}$ customers who have been with the firm $t$ periods before. Therefore the firm's total number of customers is

$$
\left(\sum_{t=1}^{\infty} B_{h^{t}}^{t}\right)+n .
$$

Therefore the total number of consumers is $\mathrm{nB}_{h}$. If $n$ customers arrive every period and the expected number of customers stays constant at $\mathrm{nB}_{h}$ then the expected number of customers that leave each period is also $n$. That is, on average $d_{h}$ of the firm's total customers leave each period. The case for a low quality firm is obviously similar.

(2) It is clearly sufficient to show that $B_{h}^{t} \geq B_{l}^{t}$ for every t. Choose any tmandix it. Let $\Gamma_{h}$ and $\Gamma_{\mathcal{T}}$ be the random vector of $t$ repetitions of, respectively, $\gamma_{h}$ and $\gamma_{l}$.

$$
\begin{aligned}
& \Gamma_{h}=\left(\gamma_{h}, \gamma_{h}, \ldots, \gamma_{h}\right) \\
& \Gamma_{l}=\left(\gamma_{l}, \gamma_{l}, \ldots, \gamma_{l}\right)
\end{aligned}
$$

Let $\Delta^{\mathrm{n}}$ be $\{h, \ell\}^{\mathrm{n}}$. Therefore $\Delta^{\mathrm{t}}$ is the range of $\Gamma_{h}$ and $F_{\ell}$. Let $\delta \in \Delta^{\mathrm{t}}$. We will write $\delta=\left(\delta_{1}, \delta_{2}, \ldots, \delta_{t}\right)$. Let $\mathrm{P}_{h}$ and $\mathrm{P}_{l}$ be the random vectors of the first $t$ probability estimates. 


$$
\begin{aligned}
& \mathrm{P}_{h}=\left(\mathrm{P}_{h}^{\mathrm{P}}, \ldots, \mathrm{P}_{h}^{\mathrm{t}}\right) \\
& \mathrm{P}_{\ell}=\left(\mathrm{P}_{\ell}^{\mathrm{T}}, \ldots, \mathrm{P}_{\ell}^{\mathrm{t}}\right)
\end{aligned}
$$

Based on (3), (4), (6), and (7), recursively define the function $G: \Delta^{\mathrm{t}} \rightarrow[0,1]^{\mathrm{t}}$ :

$$
\begin{aligned}
& P_{\ell}=G\left(\Gamma_{h}\right) \\
& P_{l}=G\left(\Gamma_{l}\right)
\end{aligned}
$$

Because of the monotonicity assumption (5), (8), (9), and (10), it is clear that $G$ is also monotone. That is if $\delta$ and $\delta * \varepsilon \Delta$ and $\delta_{i}=h \Rightarrow \delta_{i}^{*}=h$ then

$$
G\left(\delta^{*}\right) \geq G(\delta)
$$

(For two vectors $x=\left(x, \ldots, x_{n}\right)$ and $y=\left(y, \ldots, y_{n}\right)$ in $R^{n}$ we say that $x \geq y$ if $x_{i} \geq y_{i}$ for every $i=1, \ldots, n_{\text {. }}$ )

Now let $\mathrm{q}$ be any vector in $[0,1]^{\mathrm{t}}$; $\mathrm{q}$ is the vector of reservation probabilities .

$$
q=\left(q_{1}, q_{2}, \ldots, q_{t}\right)
$$

We want to prove that

$$
\operatorname{Pr}\left\{G\left(\Gamma_{h}\right) \geq q\right\} \geq \operatorname{Pr}\left\{G\left(\Gamma_{\ell}\right) \geq q\right\}
$$

To do this, construct a set of random vectors $\left\{\Gamma^{i}\right\}_{i=0}^{t}$. Each random vector is a $\mathrm{t}$-tuple

$$
\Gamma^{i}=\left(\Gamma_{1}^{i}, \Gamma_{2}^{i}, \ldots, \Gamma_{t}^{i}\right)
$$

where

$$
\Gamma_{j}^{l}=\left\{\begin{array}{l}
\gamma_{h}, j \leq i \\
\gamma_{\ell}, j>i .
\end{array}\right.
$$

By definition, $\Gamma^{0}$ is $\Gamma_{\ell}$ and $\Gamma^{t}$ is $\Gamma_{h}$. Therefore, to prove (A-11) it is sufficient to show that for $i=0, \ldots, t-1$

$$
\operatorname{Pr}\left\{G\left(\Gamma^{i+1}\right) \geq q\right\} \geq \operatorname{Pr}\left\{G\left(F^{i}\right) \geq q\right\}
$$

For notational convenience $i t$ is easiest to show this fact for $i=0$ However, it will be clear that the method of proof is perfectly general. Rewrite the random vectors $G\left(\Gamma^{1}\right)$ and $G\left(\Gamma^{\circ}\right)$ as a discrete combination of two random variables.

$$
\begin{aligned}
& G\left(\Gamma^{1}\right)=\left\{\begin{array}{l}
G\left(h, \gamma_{\ell}, \ldots, \gamma_{\ell}\right), \text { with probability }(1-\alpha) \\
G\left(\ell, \gamma_{\ell}, \ldots, \gamma_{\ell}\right), \text { with probability } \alpha .
\end{array}\right. \\
& G\left(\Gamma^{0}\right)=\left\{\begin{array}{l}
G\left(h, \gamma_{\ell}, \ldots, \gamma_{\ell}\right), \text { with probability } \beta \\
G\left(\ell, \gamma_{\ell}, \ldots, \gamma_{\ell}\right), \text { with probability }(1-\beta)
\end{array}\right.
\end{aligned}
$$

Now define the following subsets of $\Delta^{t-1}$.

$$
\begin{aligned}
& \mathrm{H}=\left\{\delta \in \Delta^{\mathrm{t}-1}: \mathrm{G}(h, \delta) \geq \mathrm{q} \wedge \mathrm{G}(\ell, \delta) \not \mathrm{q}\right\} \\
& \mathrm{L}=\left\{\delta \in \Delta^{\mathrm{t}-1}: \mathrm{G}(h, \delta) \geq \mathrm{q} \wedge \mathrm{G}(\ell, \delta) \geq \mathrm{q}\right\} \\
& \mathrm{N}=\left\{\delta \in \Delta^{\mathrm{t}-1}: \mathrm{G}(h, \delta) \not \mathrm{q} \wedge \mathrm{G}(l, \delta) \not \mathrm{q}\right\}
\end{aligned}
$$

It is clear from (A-9) that $H, L$, and $N$ are disjoint and their union is $\Delta^{t-1}$. Finally, let $\Gamma_{\ell}^{t-1}$ denote the random vector of $(t-1)$-triple of $\gamma_{l}$.

$$
\Gamma_{\ell}^{t-1}=\underbrace{\left(\gamma_{\ell}, \gamma_{\ell}, \ldots, \gamma_{l}\right)}_{t-1 \text { times }}
$$

Based on this notation, we can rewrite the LHS of $(A-14)$ for $i=0$ as

$$
(1-\alpha) \operatorname{Pr}\left\{\Gamma_{\ell}^{\mathrm{t}-1} \in \mathrm{H}\right\}+\operatorname{Pr}\left\{\Gamma_{\ell}^{\mathrm{t}-1} \in \mathrm{L}\right\} \text {. }
$$


We can rewrite the RHS of $(A-14)$ for $i=0$ as

$$
\beta \operatorname{Pr}\left\{\Gamma_{\ell}^{t-1} \in H\right\}+\operatorname{Pr}\left\{\Gamma_{l}^{t-1} \in L\right\} .
$$

Because $\beta \leq 1-\alpha,(A-20)$ is less than or equal to $(A-19)$.

\section{Proposition 3:}

Totally differentiate the system of equations (39) - (43) to yield

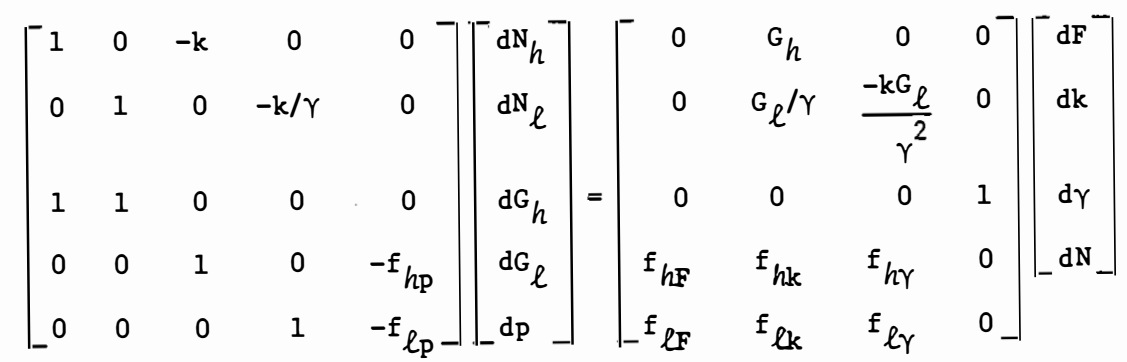

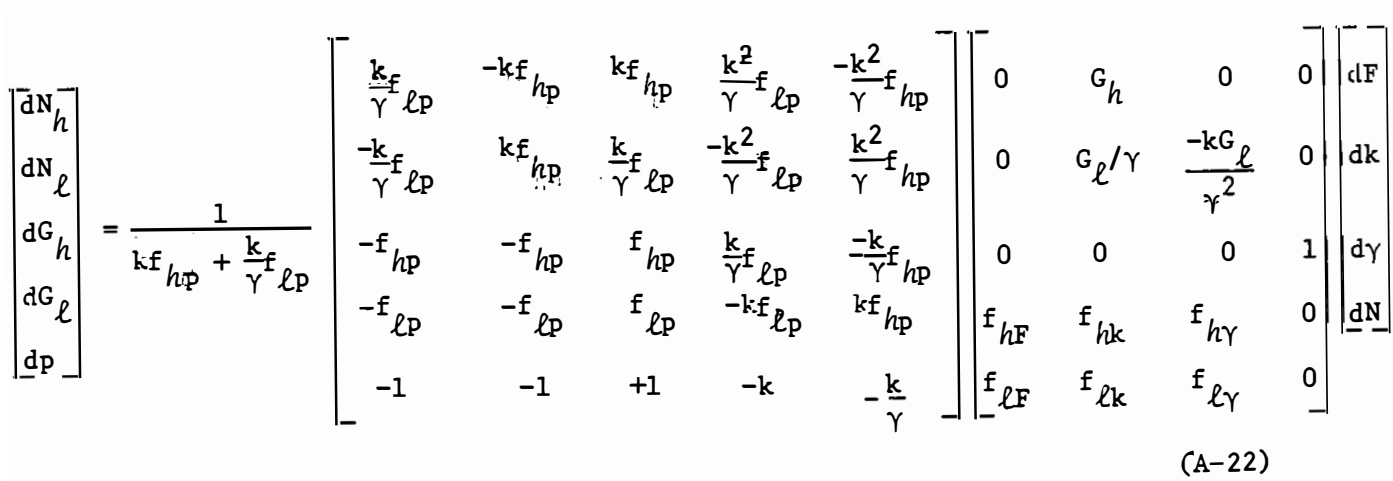

Therefore we have

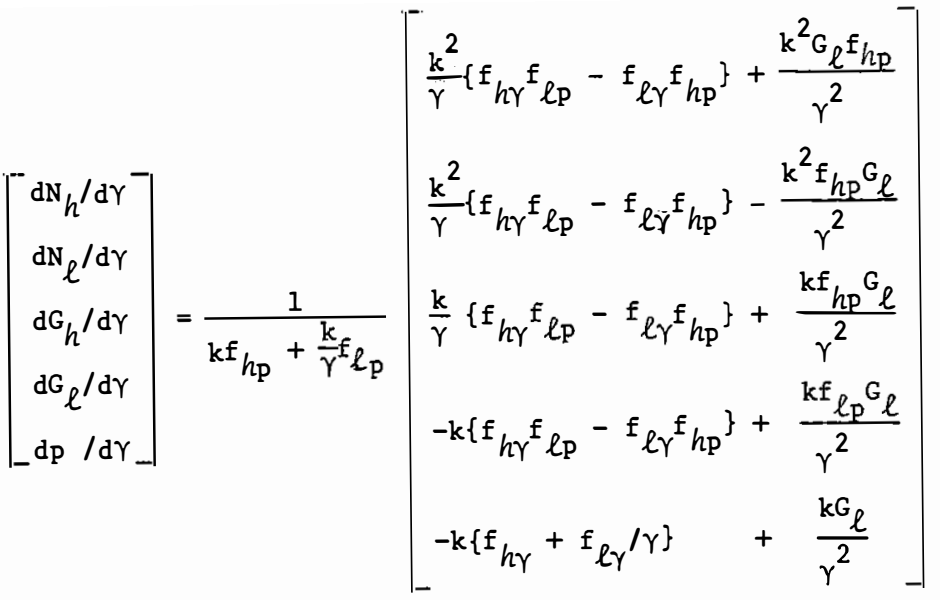

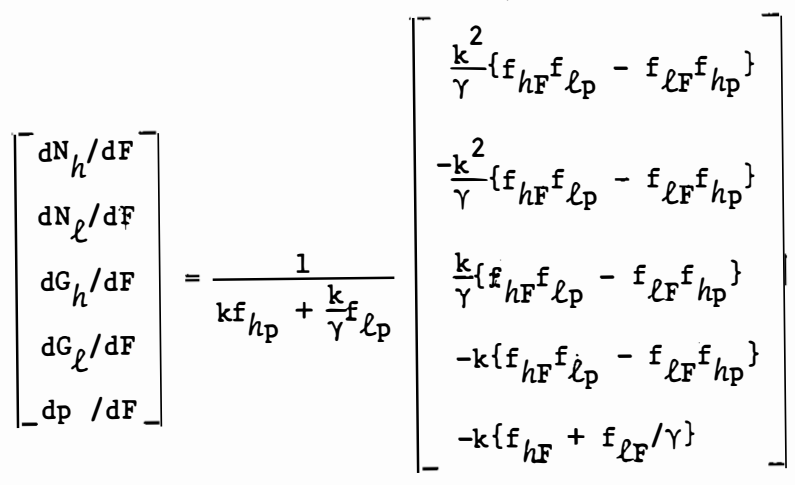

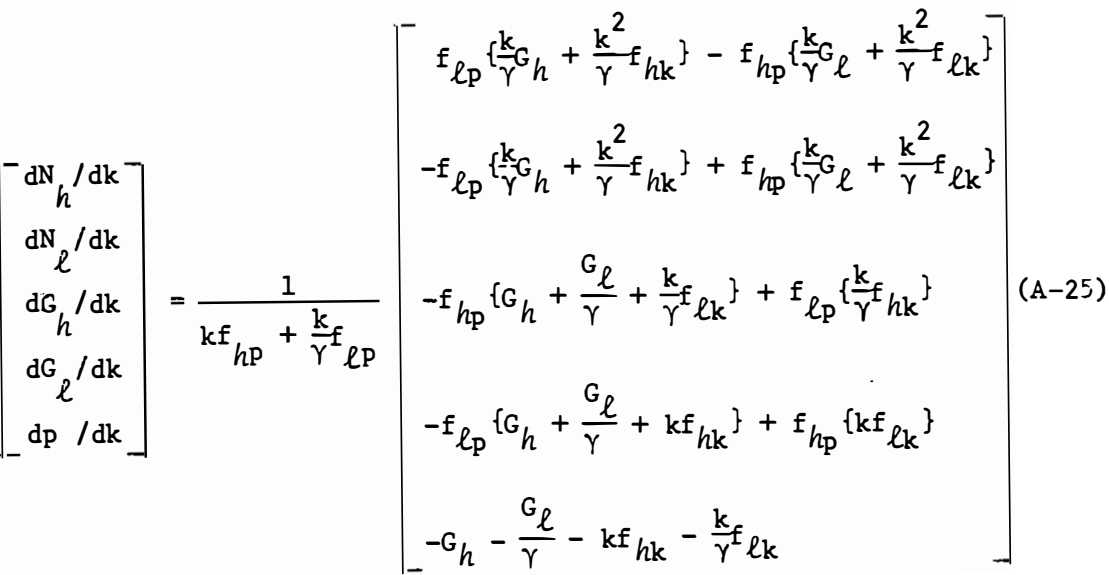




$$
\left[\begin{array}{c}
\mathrm{dN}_{h} / \mathrm{dN} \\
\mathrm{dN}_{\ell} / \mathrm{dN} \\
\mathrm{d} G_{h} / \mathrm{dN} \\
\mathrm{d} G_{\ell} / \mathrm{dN} \\
\mathrm{dp} / \mathrm{dN}
\end{array}\right]=\frac{1}{\mathrm{kf}_{h_{\mathrm{p}}}+\frac{\mathrm{k}_{\mathrm{f}}}{\gamma} \ell_{\mathrm{p}}}\left[\begin{array}{c}
\mathrm{kf}_{h_{\mathrm{p}}} \\
\frac{\mathrm{k}_{\mathrm{f}}}{\gamma} \ell_{\mathrm{p}} \\
\mathrm{f}_{h_{\mathrm{p}}} \\
\mathrm{f}_{\mathrm{p}} \\
1
\end{array}\right] .
$$

Now a number of terms need to be signed to prove the Proposition.

I will list each term and its sign as a claim and then prove it.

Claim 1: $\quad \mathrm{kf}_{h \mathrm{p}}+\frac{\mathrm{k}_{\mathrm{f}}}{\gamma \ell_{\mathrm{p}}} \geq 0$.

Proof:

By Proposition $2-(1), f_{h p} \geq 0$.

By Proposition 2 - (5) $f_{h p}+f_{l p} \geq 0$.

As well, $\gamma \geq 1$.

Therefore

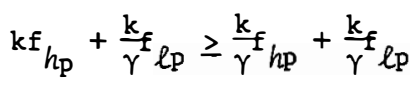

$$
\begin{aligned}
& =\frac{k}{\gamma}\left(f_{h p}+f_{l p}\right) \\
& \geq 0 \text {. }
\end{aligned}
$$

Claim 2: $\quad f_{h{ }^{f} l_{p}}-f_{\ell{ }^{f} h_{p}} \geq 0$
Proof:

By Proposition 2, $f_{h_{P}} \geq 0$ and $f_{h_{P}}+f_{\ell_{P}} \geq 0$. Therefore either $\left|f_{h_{p}}\right| \geq\left|f_{l p}\right|$ or $f_{l p} \geq 0$ is true.

By Proposition 2, $f_{h \gamma} \geq 0, f_{\ell \gamma} \leq p$, and $f_{h \gamma}+f_{\ell \gamma} \leq 0$.

Therefore $\left|\mathrm{f}_{\ell \gamma}\right| \geq\left|\mathrm{f}_{h \gamma}\right|$.

Suppose that $\left|f_{h p}\right| \geq||_{\ell p} \mid$. Then

$$
\left.\begin{array}{l}
\left|\mathrm{f}_{h p}\right| \geq\left|\mathrm{f}_{\ell p}\right| \\
\left|\mathrm{f}_{\ell \gamma}\right| \geq\left|\mathrm{f}_{h \gamma}\right|
\end{array}\right\} \Rightarrow\left|\mathrm{f}_{h p} \mathrm{f}_{\ell \gamma}\right| \geq\left|\mathrm{f}_{\ell p} \mathrm{f}_{h \gamma}\right| .
$$

Since $-f_{h p} f_{\ell \gamma} \geq 0$, Claim 2 is true. Now suppose that $f_{l_{p}} \geq 0$. Then Claim 2 is clearly true because both terms in the sum are non negative.

Claim 3: $\mathrm{f}_{h F^{\mathrm{f}}{ }_{\ell p}}-\mathrm{f}_{\ell \mathrm{F}^{\mathrm{f}}{ }_{h p}} \geq 0$.

Proof:

The proof is similar to that of Claim 2. $\square$ Proposition 3 now follows directly.

Lemma 1:

Let $h_{t}$ be the probability that the consumer patronizes a high quality firm at time $t$. The consumer's probability of leaving a high quality firm is $d *$. His probability of leaving a low quality firm is d Given that he leaves his current firm, his probability of arriving at a high quality firm is $a * G_{h} /\left(G_{l}+a * G_{h}\right)$ and at a low quality firm is $G_{\ell} /\left(G_{\ell}+a{ }^{*} G_{h}\right)$. Therefore, we can write 


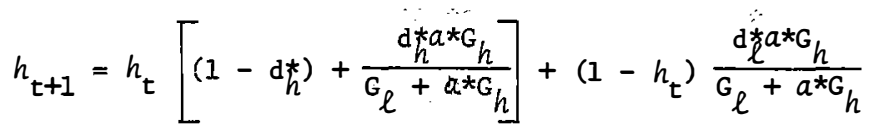

This Markov process converges to $h \star$. The value for $l \star$ can be directly calculated in the same fashion or can simply be calculated by subtracting $h *$ from 1 .

\section{Proposition 4:}

The solution to (54) satisfies

$$
\theta_{1}(x, x)\left(u_{h}-u_{\ell}\right)-s^{\prime}(x)=0
$$

The solution to (55) satisfies

$$
\left[\theta_{1}(y, y)+\theta_{2}(y, y)\right]\left(u_{h}-u_{\ell}\right)-s^{\prime}(y)=0 .
$$

These are different so long as $\theta_{2}(x, x) \neq 0$. By assumption the LHS of $(A-30)$ slopes down. Therefore if $\theta_{2}(q, q)$ is positive for every $q$, the LHS of (55) intersects the axis at a point to the right of $x$.

\section{FOOTNOTES}

1. As explained in the introduction, this mathematics can also be interpreted to model a situation where a firm attempting to produce high (low) quality goods does not have complete control over the process and thus sometimes produces low (high) quality goods. Then the assumption that $\alpha+\beta<1$ means that a firm attempting to produce high quality goods is more likely to produce high quality goods than is a firm attempting to produce low quality goods.

2. It is being assumed that firm size does not affect relative arrival rates. Nelson (1976) has correctly pointed out that larger firms might be better able to establish a reputation for a number of reasons. Such a modification should not substantially change the analysis.

3. Fixed costs are written as $F+F_{i}$ instead of merely as $F_{i}$ so that the parameter $\mathrm{F}$ can be varied for comparative statics.

4. Schmalensee (1978) also uses this objective function to derive his comparative statics.

5. As a convention, the firm chooses to produce when the best production process yields zero profits and chooses to produce high quality when 
production of either high or low quality yields identical non negative profits.

6. This result depends on the supply curve sloping upward in price. This is proven in the Appendix in the proof to Proposition 3 under Claim 1 .

7. Recall the discussion surrounding equation (29) concluded that the profits from high quality production relative to low quality production rise as price rises.

8. Satterthwaite (1979) considers such a model. Not surprisingly, he models information transfer as an exchange of facts about the specific aspects of a firm's quality. Satterthwaite also allows parties to exchange secondhand information and to possess memories of previous exchanges. He can manage such an elaborate model because it is not necessary for him to consider explicitly the nature of the information transferred, only the amount. This is a fruitful area for further research.

9. In previous sections $q$ was allowed to depend on $t$. A reading of Rubinstein (1979) suggests that the optimal reservation probability will vary with $t$. For this section it is easier to analyze the optimal choice of the consumer if the domain is the real line.

Instead of simply assuming the reservation probability is constant over time, we could view the consumer as already having performed a partial optimization. Let $\mathrm{q}$ be associated with the best policy in the class of policies whose average is $q$.

10. The simplifying assumption is not that consumers assume $G_{h}$ and $G_{\ell}$ to be constant when choosing a value of $q$. It is reasonable for consumers to exhibit behavior of this sort. This is similar to the behavior of firms assumed in Section III -- they assume their actions do not affect relative firm size. Both sets of behavior derive from the fact that individual agents are a very small part of the market and the assumption of Nash behavior. The simplifying assumption being made in this section involves calculation of the optimal level of $q$. There are actually two separate issues involved in determining whether consumers choose an optimal level of $\mathrm{q}$. One is whether the non-cooperative choice of $q$ by a consumer adequately takes into account the benefit that he confers on all other consumers by changing $G_{h}$ and $G_{\ell}$. The other is whether non-cooperative choice of $q$ by a consumer adequately takes into account the benefit that he confers on all other consumers through the recommendations he gives to them. I isolate the second issue by assuming that $G_{h}$ and $G_{l}$ are constant when calculating an optimal level of $q$ with which to compare the consumer's choice. It seems intuitive that the first factor would reinforce the second -- the optimal level of $q$ is higher and involves more search than the chosen level. However, I have formally only analyzed the second factor. 


\section{REFERENCES}

Ackerlof, George A. "The Market for 'Lemons': Quality Uncertainty and the Market Mechanism." Quarterly Journal of Economics 84 (August 1970) :488-500.

Benham, L. and Benham A. "Regulating the Professions: A Perspective on Information Control." Journal of Law and Economics. 18 (1975) : 421-447.

Darby, Michael R. "Qualitative Information, Reputation, and Monopolistic Competition." Mimeo, March 4, 1976.

and Karni, Ed. "Free Competition and the Optimal Amount of Fraud." Journal of Law and Economics 16 (April 1973) : 67-88.

Dybvig, Philip H. and Spatt, Chester S. "Does It Pay to Maintain a Reputation?" Mimeo.

Green, Edward. "Agency, Information and Cooperation over Time." Mimeo, February 1980.
Klein, Benjamin and Leffler; Keith B. "The Role of Price in Guaranteeing Quality." UCLA Discussion Paper No. 149.

Macauley, Stewart. "Non-Contractual Relations in Business: A Preliminary Study." American Sociolog1cal Review 28 (February 1963):55-69.

Nelson, Phillip. "Information and Consumer Behavior." Journal of Political Economy 78 (1970): 311-329.

Radner, Roy. "Collusive Behavior in Noncooperative Epsilon-Equilibria of Oligopolies With Long but Finite Lives." Bell Labs Discussion Paper \#144, August 1979.

Rothschild, Michael. "Models of Market Organization with Imperfect Information: A Survey." Journal of Political Economy 81 (December 1973):1238-1308.

Rubinstein, Ariel. "An Optimal Conviction Policy for Offenses that May Have Been Committed by Accident," Hebrew University Department of Economics Research Report No. 114, January 1979.

Salop, S. "Information and Monopolistic Competition." American Economic Review 66 (May 1976):240-245. 
, and Stiglitz, J. "Bargains and Ripoffs: A Model of Monopolistically Competitive Price Dispersion." Review of Economic Studies. 44 (1977):493-510.

Satterthwaite, Mark A. "Consumer Information, Equilibrium Industry Price, and the Number of Sellers." Bell Journal 10 (1979): 483-502.

Schmalensee, R. "A Model of Advertising and Product Quality." Journal of Political Economy 86 (1978):485-504.

Wilde, Louis L. and Schwartz, Alan. "Equilibrium Comparison Shopping." Review of Economic Studies 46 (July 1979):543-553. 